IZA DP No. 6517

The International Migration of Health Professionals

Michel Grignon

Yaw Owusu

Arthur Sweetman

April 2012 


\title{
The International Migration of Health Professionals
}

\author{
Michel Grignon \\ McMaster University \\ Yaw Owusu \\ McMaster University \\ Arthur Sweetman \\ McMaster University \\ and IZA
}

\section{Discussion Paper No. 6517 \\ April 2012}

IZA
P.O. Box 7240
53072 Bonn
Germany

Phone: +49-228-3894-0

Fax: +49-228-3894-180

E-mail: iza@iza.org

\begin{abstract}
Any opinions expressed here are those of the author(s) and not those of IZA. Research published in this series may include views on policy, but the institute itself takes no institutional policy positions.

The Institute for the Study of Labor (IZA) in Bonn is a local and virtual international research center and a place of communication between science, politics and business. IZA is an independent nonprofit organization supported by Deutsche Post Foundation. The center is associated with the University of Bonn and offers a stimulating research environment through its international network, workshops and conferences, data service, project support, research visits and doctoral program. IZA engages in (i) original and internationally competitive research in all fields of labor economics, (ii) development of policy concepts, and (iii) dissemination of research results and concepts to the interested public.
\end{abstract}

IZA Discussion Papers often represent preliminary work and are circulated to encourage discussion. Citation of such a paper should account for its provisional character. A revised version may be available directly from the author. 
IZA Discussion Paper No. 6517

April 2012

\section{ABSTRACT}

\section{The International Migration of Health Professionals ${ }^{*}$}

Health workforce shortages in developed countries are perceived to be central drivers of health professionals' international migration, one ramification being negative impacts on developing nations' healthcare delivery. After a descriptive international overview, selected economic issues are discussed for developed and developing countries. Health labour markets' unique characteristics imply great complexity in developed economies involving government intervention, licensure, regulation, and (quasi-)union activity. These features affect migrants' decisions, economic integration, and impacts on the receiving nations' health workforce and society. Developing countries sometimes educate citizens in expectation of emigration, while others pursue international treaties in attempts to manage migrant flows.

JEL Classification: J61, I15, I18

Keywords: migration, health professionals, international medical graduates

Corresponding author:

Arthur Sweetman

Department of Economics

McMaster University

Hamilton, Ontario L8S 4M4

Canada

E-mail: arthur.sweetman@mcmaster.ca

\footnotetext{
* This paper is forthcoming as a chapter in the International Handbook on the Economics of Migration. We would like to thank the editors and an anonymous referee for helpful comments that have improved the manuscript.
} 


\section{INTRODUCTION}

International migration by health professionals is an area of increasing policy interest. Shortages of medical personnel in several developed countries are perceived to be central drivers of this phenomenon, and there are critical ramifications for developing countries (e.g., World Health Organization - WHO, 2006). After a period of perceived excess supply in many developed countries in the 1990s, more recent years have seen an increased demand for health professionals, a growing concern about the need to provide healthcare services to aging populations, and an increasing focus on health human resources more generally.

The International Migration Outlook (Organization for Economic Cooperation and Development - OECD, 2007a) identifies "several international initiatives ... formulating policy

recommendations to overcome the global health workforce crisis" (p.162). ${ }^{1}$ In response to these flows, in 2010 the WHO adopted a global code of practice on the international recruitment of health personnel with a focus on ethics and protecting less-developed sending countries (WHO, 2010). Aligned with this initiative, several developed countries have devised their own protocols regarding the ethics of international health professional migration (e.g., Canada's ACHDHR, 2009; Norway’s Directorate of Health and Social Affairs, 2007; UK Department of Health, 2011). Moreover, migration among more developed countries is also an issue. In particular, the enlargement of the EU has heightened concerns regarding an exodus of health workers from accession countries towards Western Europe (Wismar et al., 2011).

A substantial amount of academic research by health clinicians, health services researchers, migration scholars, and those from other backgrounds, together with significant contributions from international organizations, advocacy groups, and others has explored the 
broad issue of health workforce migration. Economists are adding a particular perspective to this interdisciplinary discussion, but much work remains to be done. This paper surveys the topic from an economic perspective while also being situated within the broader interdisciplinary literature. Moreover, this survey employs selected well-known theoretical tools from economics in an effort to conceptualize the substantive phenomenon and to point to areas for future research. After this introduction, the second section provides an empirical overview to elucidate the magnitudes of international flows of health professionals and set the context for the analysis that follows. In the third section the focus is on developed countries, which implies simultaneously addressing issues regarding both receiving and sending health workforce migrants. Lessdeveloped, primarily sending, countries are addressed in the fourth section. The final section concludes.

\section{DESCRIPTIVE STATISTICS OF THE INTERNATIONAL CONTEXT}

International comparisons and analyses of health human resources have become much easier in recent years because of the work of the WHO and the OECD. Building on this, Figure 1 depicts the percentage of physicians that are foreign born in a wide variety of (mostly) OECD countries circa 2000 and compares it to the percentage of the entire population that is foreign born. It is clear that in almost all countries immigrants are much more likely to be physicians than are native born persons, Germany and Greece being notable exceptions. Most OECD countries import a very substantial share of their physicians. In contrast, in Figure 2 nurses are seen to be, on average, roughly proportionately drawn from each country's immigrant and native born populations, although there is also greater variation across nations for nurses with some

\footnotetext{
${ }^{1}$ A useful summary of the shortages and maldistribution of the health workforce is the OECD's (2008) report: The
} 
nations drawing a disproportionate share of their nursing workforce from the immigrant population and others doing the reverse. Clearly, there are important differences in the migration of physicians and nurses. Figure 3 displays a similar plot for the aggregation of a variety of other health professions. On the whole, these other professions look more like physicians than do nurses, with a disproportionate share of these health workers being drawn from the migrant population.

Of course, being foreign born does not imply being foreign educated since immigrants may arrive in their host country prior to completing their education. Also, the aptly named 1.5 generation - those who immigrate as children - may have a different probability of obtaining health professional certification than does the average native born person. This difference is addressed in Table 1. The traditional immigrant receiving countries of Australia, Canada, and New Zealand clearly have a substantial number of immigrants educated in the domestic school system; surprisingly the US does not. Also, in France and Portugal a substantial proportion of the foreign-born are educated domestically, although as noted in OECD (2007a) this may reflect the repatriate community.

Conversely, being native born does not imply receiving a domestic health professional education. An increasing phenomenon is the emergence of medical and other health professional schools offering education for export. Such institutions provide medical and other health professional education to an international clientele of foreign students as an export industry. The best known of these medical schools are probably in the Caribbean, Ireland, and more recently Australia. This implies that there are increasingly two major types of international medical and other health professional graduates: residents/citizens of the country providing their education who emigrate post-graduation, and international students who obtain their medical/health 
professional education at an international "destination" school with the primary intention of departing that country to return home or to practice in some third nation. This is particularly the case for the US where, for physicians, the American Medical Association (AMA - 2010) reports that in 2008 about 15 per cent of International Medical Graduates (IMGs) among those in Accreditation Council for Graduate Medical Education programs are native US citizens. ${ }^{2}$ Of course, as discussed by Hawthorne and Hamilton (2010), countries housing such medical schools may also come to view these foreign students as a source of potential domestic supply. In fact, it could be argued that from some perspectives this is an ideal supply since it is both inexpensive, with the students paying international student fees, and the graduates are already fully acclimatized to local medical practice.

This (increasingly) revenue generating education for non-residents is distinct from the well-known practice of some countries training their citizens with the explicit intent of serving international markets with migrants - such as some Philippine and Indian medical and nursing schools (Masselink and Lee, 2010; Nullis-Kapp, 2005).

Cycling and permanent migration among developed countries is also quite common, as discussed more broadly in the chapter on circular migration in this volume. For example, Mullan (2005) provides a useful description of the flows of domestic physicians among Australia, Canada, the UK, and the US, summary statistics from which are presented in Table 2. At the top is the UK and Canada, both of which are net exporters in this quadruple, and at the bottom are Australia and the US, which are net recipients. ${ }^{3}$ Turning to nurses, the OECD (2007a) takes a somewhat broader view looking at all intra-OECD migration and characterizing it as having a cascading-pattern. Australia and Canada, and to a lesser extent Great Britain, New Zealand, and

\footnotetext{
${ }^{2}$ This can be thought of as the flow of new MD graduates. Given the integration of Canadian and American medical education, graduates of Canadian medical schools are not classified as IMGs in the US.
} 
Switzerland, are positioned near the bottom of the chain and receive nurses from other OECD nations. However, similar to the situation for physicians, the US is at the very bottom of this migratory flow and is by a substantial amount the largest net recipient of immigrant nurses. Given the enlargement of the EU - and associated treaties and regulations regarding the mutual recognition of credentials - substantial geographic mobility within that area is observed and more is expected, although to date there has perhaps been less mobility than some feared (Wismar et al., 2011).

\section{A DEVELOPED COUNTRY PERSPECTIVE}

This section addresses three questions. Why do rich countries import health professionals? How do these immigrant health professionals fare in the healthcare market of recipient countries? And, what are the impacts of licensure and other specific institutions of the healthcare market in recipient countries on the integration of foreign-trained professionals?

\section{Health Labour and Product Markets - Brief Overview}

Before focusing on the international migration of the health workforce it is worth briefly considering relevant economic aspects of health product and factor markets since these are crucial for interpretation. As is well-known, the product market for health services is nonstandard, and asymmetric information problems are extremely serious. Most health service provision is "custom work" employing specialized knowledge that makes it very costly to judge provider effort and the quality of the work performed. Principal-agent models are also often employed to characterize the context, as are models of monopolistic competition (see, e.g.,

\footnotetext{
${ }^{3}$ Of course, when all nations are included then all of these four countries are net recipients.
} 
McGuire, 2000). It is not even clear that the patients/customers have sufficient information to know the optimal quantity of services to purchase leading to (somewhat controversial) models of supplier induced demand whereby if providers (usually physicians) perceive that they do not have sufficient business/income they can influence the demand for additional services (McGuire, 2011). One ramification of professional knowledge and other sources of asymmetric information is licensing and/or regulation by government, which is frequently delegated to a professional college or similar organization of experts. Licensing bodies become important hurdles for the international migration of health professionals, and it is often argued that in addition to simply verifying ability/credentials these organizations serve to create provider monopoly power, as will be discussed below.

Another important determinant of the structure of healthcare product markets is the potential occurrence of infrequent unanticipated large-scale expensive negative health shocks in contexts where borrowing is not normally feasible. One response to this is private health insurance, which is ubiquitous in developed countries. Health insurance can be viewed as a payin-advance approach to funding healthcare service purchases that spreads risk across the population. However, "pure” insurance is not sufficient in healthcare markets since there are individuals whose health status (sometimes from birth) is uninsurable in an actuarially fair system. This would lead to a profound - and morally/ethically unacceptable - market failure. However, society in the form of government intervenes to provide (or at least pay for and/or subsidize) healthcare services.

In practice, government for various reasons normally provides far more healthcare services than those medically necessary because of this example of a market failure. Although the structure of healthcare systems and the nature and extent of governments' roles vary 
dramatically across nations, in most developed countries governments play a very significant role in the operation of the healthcare system. In terms of international migration, this institutional structure serves frequently to separate healthcare recipients (that is, patients) from those who in the first instance pay for those services (that is, governments, insurance companies, patients and others). This separation of the "payer" from the recipient adds an important characteristic to the marketplace. The aggregate-level payers are concerned about costs, but akin to patients, they face asymmetric information challenges regarding courses of treatment for individuals. In an effort to control costs governments in particular sometimes seek to control the number of providers, which has a variety of quite complex ramifications for the international migration of health professionals.

On the factor market side it is important to recognize the enormous time lags in training health professionals, especially physicians, which can lead to a type of "overshooting" whereby a perception of a current surplus generates a cap on or a reduction in enrolments, which seems frequently to lead to a shortage in the medium- to long-term (see, e.g., Bärnighausen and Bloom, 2011, for a survey of the literature). In large part these caps are motivated by concerns about cost containment. For example, there are caps on both undergraduate (MD) and graduate (specialty/residency) positions in the US (AMA, 2010), ${ }^{4}$ and the central governments of Australia, France, Sweden, and the UK control medical school enrolment through university funding. Some countries, such as Canada, have a more decentralized, though still government mandated, approach with each province setting local medical enrolment. ${ }^{5}$ Mis-targeting can lead to oscillating periods of (perceived) surplus and shortage, as have been observed in recent

\footnotetext{
${ }^{4}$ In 1997 the Balanced Budget Act froze the number of resident physicians at 1996 levels. Currently, a 2009 bill to increase resident physician positions by $15 \%$ is pending in the U.S. Congress.

${ }^{5}$ Not all countries follow this approach. In Germany, for example, there is no centralized control over the size of the medical workforce.
} 
decades (Bloor and Maynard, 2003). Given the extended training periods of physicians and other health professionals, almost by default international migration is used as a short-term quantity adjustment mechanism.

From a different perspective, employers/payers in healthcare are frequently viewed as monopsonistic, especially for nurses (e.g., Hirsch and Schumacher, 2005; Machin and Manning, 2004; Staiger, Spetz and Phibbs, 2010), although there is some controversy. Monopsony explains the ongoing perception of shortages concurrent with unemployment or underemployment in the sector and/or a queue of potential immigrant workers willing to work at the going wage who are prevented from practicing in the relevant profession. Simultaneously, public-sector unionization also plays an extremely important role, with some professional associations/unions in healthcare having enormous influence (see, e.g., Drexler, 2008). In fact, in some jurisdictions health human resource decisions might best be viewed as the outcomes of a bilateral monopoly with governments on one side and professional unions/associations on the other. Of course, there are usually also many influential economic actors, such as associations of hospital administrators, medical schools, and accreditation bodies as well as patient advocacy groups and policy think tanks among others. All of these combine to determine the "pull" factors that attract health workers to developed countries or act to limit their entry into national labour markets.

\section{Why Do Developed Countries Import Health Professionals?}

It is not immediately obvious why developed countries would want to import health professionals en masse. Although a small number may be involved in entrepreneurial health research or delivery with substantial spillovers for the domestic economy and that provides an economic justification for the receiving country, this is unlikely to represent the majority of 
migrants. In many countries these are "good" jobs that are rationed among a domestic population eager to become health professionals, especially physicians, but prevented from doing so via quotas on, in particular, medical school entry. ${ }^{6}$ We, therefore, next discuss a few candidate explanations for the acceptance of health professional migration by many developed countries though certainly not all, as evidenced by Germany.

A key rationale for the international migration of health professionals is a response to perceptions of short-term shortages - although these can alternate with perceptions of surpluses that can induce barriers to entry. ${ }^{7}$ As mentioned, governments have multiple incentives for managing the size of the workforce for physicians and other health providers, especially cost containment. Other payers as well as provider associations have similar incentives, though different objective functions, but ultimately governments have the authority to act whereas the others only have influence. Further, governments can and do overshoot - more frequently toward shortages than surpluses. Given the extended education/training durations (planning horizons) involved, international migration is frequently used by wealthy countries as a tool to manage short-term shortages. An interesting variation on this theme is put forward by Rutten (2009a) who, using a computable general equilibrium model for the UK, and very specific assumptions, argues that for some situations importing immigrant health providers has superior welfare

\footnotetext{
${ }^{6}$ This is, in part, evident in the increasing number of individuals from developed countries, especially the US and Canada as reported by McAvinue et al. (2005), who pursue their education in "destination" medical schools. See, for example, St. George's school of medicine in Grenada (http://www.sgu.edu/about-sgu/medical-studentsdemographics.html; Dec. 2011), which in 2011 had 3,272 US citizens (68\% of its total) as students in its medical program. Canadians were the next largest group at 15\% (665 students), while native Grenadians accounted for only $5 \%$ of total MD enrolment. Hawthorne and Hamilton (2010) provide an accounting of foreign student enrolment in Australian medical schools. There is a substantial number of individuals who meet the requirements for entrance to medical school, are willing to pay very substantial tuition, and end up practicing in their native or some other developed country via this circuitous international route.

${ }^{7}$ It is worth noting that payer, provider, and patient perceptions of the adequacy of the supply of health professionals are not necessarily in accord. An overview of the history of forecasting in this area is by Bärnighausen and Bloom (2011).
} 
implications to increasing the health service's budget since the former avoids pay increases for inframarginal (existing) workers.

A related but distinct rationale involves local or specialty-specific shortages (Zurn et al., 2004). Rural, remote, and underprivileged areas are underserviced by domestic health professionals in many developing (e.g., Kanchanachitra et al., 2011) and developed (e.g., Rabinowitz et al., 2008) countries. Surprisingly, for an important issue that has been a focus of discussion for decades, there are essentially no studies that credibly estimate medium- and longterm causal impacts of programs seeking to address health services provision in underserviced areas; systematic reviews that have found no such studies are by Grobler et al. (2009) and Wilson et al. (2009). Nevertheless, there is a large research literature looking at non-causal relationships, and some jurisdictions, particularly Australia, Canada, New Zealand, and the US, clearly and explicitly employ immigration as a tool to service rural and remote areas (for a survey of one aspect of this literature see Bärnighausen and Bloom, 2009). To tie them to appropriate geographical areas, at least in the short run, such workers are frequently admitted under limited visas, for example J-1 visas in the US (e.g., Hagopian et al., 2003, US GAO, 2006) or given limited/provisional licenses to practice in Australia and Canada (e.g., Auda et al., 2005). Secondary migration by international migrants, and internal migration more generally, is a key mechanism explaining why underserviced areas have been the focus of an ongoing policy issue for decades as described by McDonald and Worswick (2010) for Canada. They focus on out migration from underserviced rural areas that actively recruit IMGs, and in the Canadian case physicians practicing in these regions also typically receive additional financial and nonfinancial benefits. Their research observes low retention rates, which are not entirely associated with pecuniary factors but have substantial relationships with marital status and spouse's level of 
education. Further, the migrants tend to move not to other underserviced areas, nor to regions with intermediate levels of service, but to the very largest cities with the highest physician densities. Overall, regions with the greatest need and lowest entry hurdles are effectively stepping stones to other locations within the country for many IMGs. Although the international migration of health professionals clearly provides practitioners to underserviced areas, it appears that a steady flow of such practitioners is required.

Closely related to finding workers for geographic locations that are (by some) deemed less desirable, is the need to find health workers for less desirable work shifts (times of the day/week) and other practice characteristics (e.g., Drexler, 2008; Denour and Junker, 1995). Again, immigrants tend to be found working in these situations - at least initially upon arrival in a new country. Lastly, it has been suggested that importing countries should try to match their increasingly diverse population through importing physicians of the same ethnic backgrounds who would be more culturally sensitive than native-born and locally educated ones. There is not, however, clear evidence that sharing the same ethnic background makes healthcare professionals more effective. A fuller exposition of migration, ethnicity and economic integration can be found in the lead chapter to this volume.

Since the education and training of health professionals is both subsidized and costly to government in many countries (e.g., McGuire, 2000), savings on these fronts is sometimes suggested as motivating immigration. While this may indeed prompt some short-term decisions, it's hard to believe that governments would be sufficiently myopic (and insensitive to the demands of prospective domestic health/medical students) as to drive policy based on these upfront costs that are relatively modest as a percentage of total healthcare expenditures. 
Population aging is an often mentioned rationale for health worker migration. However, the link to the demand for immigrant health professionals is more tenuous than it might at first appear. It is not a short term problem but one of the few public policy issues that can be forecast decades in advance. Also, while the associated increased demand for health professionals cannot be ignored, it is more modest than popular perceptions allow although there is a need to alter the composition of the health professional workforce since demand will shift from, for example, pediatrics, obstetrics and gynecology to ophthalmology and chronic diseases (e.g., Denton, Gafni, and Spencer, 2009). On the other hand the story is quite different for low skilled healthcare providers since, as Haberkern et al. (2012) point out, the need for elder care will likely increase substantially in rich countries. Because home and long-term care are labour intensive, with limited possibilities for automation, lower skilled healthcare workers from developing or less rich countries will probably supply it in wealthier nations. Canada's "live-in caregiver program" is a formalized immigration stream that is increasingly used for elder care, whereas it was formerly primarily used for childcare.

\section{The Labour Market Integration of Health Providers}

Unlike much of the immigration literature, there has been relatively little analysis of economic integration that is specific to health professionals. However, recent work using US data by Schumacher (2011) has begun to address this issue for nurses as a precursor to looking at the impact of immigration on domestic workers in that occupation, and it is worth reviewing this article at length. Using the US National Council Licensure Examination where candidates are required to pass qualifying exam(s) that are set by a third party rather than an educational institution where the conflict of interest between pedagogical delivery and assessment is obvious, 
Schumacher initially observes that first time internationally educated test takers have pass rates roughly 20 per cent below those of US-educated ones. This influences the interpretation.

Schumacher employs two datasets in his analysis: the US Current Population Survey (CPS), and the National Survey of Registered Nurses (NSRN). Only country of birth is identified in the CPS, whereas the NSRN records country of education. CPS descriptive statistics show that while the foreign-born have hourly earnings slightly below that of the native born, the average wage of those with foreign education is higher. However, controlling for observed characteristics, the foreign-born have earnings about 5 to 8 per cent less than the US born, although there is no difference for those from Canada, and the gap is less than 3 per cent (and not statistically significant) for those from the Philippines - the second largest and largest source countries respectively. Also, the years since migration profile suggests that full earnings equality occurs within about six years. Data from the NSRN show effectively no gap in average wages between the domestic and foreign educated, and the years since migration profile indicates even swifter integration.

One aspect of the specifications employed is that they may "over-control" for background variables. For example, some models control for union membership and others for hospital employment. While these variables are undoubtedly important, it is entirely possible that they are determined simultaneously with wages and may mask relevant wage effects. If immigrant nurses are, for example, less likely to obtain "good" union jobs or are differentially likely to be employed in hospitals because of their immigrant status, then controlling for these factors may answer an economic/policy question different than the one being posed. Future work could include specifications with and without these potentially endogenous regressors to see how the coefficient on the variable of interest changes. Similarly, a specification excluding those who 
immigrated younger than age 25 could differentiate between individuals most likely to have been educated in the US and those educated elsewhere. As seen in Schaafsma and Sweetman (2001) for example, there is a noticeable difference in labour market outcomes between those who immigrate as children and are educated domestically and those who immigrate later in life. Nevertheless, overall the evidence indicates that practicing immigrant nurses have hourly earnings that are extremely similar to those of the domestic born. Of course, these results are for practicing nurses and say nothing about outcomes for those who immigrated intending to practice, but who are not doing so.

Schumacher next attempts to estimate the impact of immigrant nurses on the wages of domestic nurses, which is very similar in intent to work by Kaestner and Kaushal (2012) who use the NSRN. However, the two take distinct methodological approaches. Schumacher employs a "factor proportions" methodology that exploits (potential) changes in wage gaps between nurses and other occupations not affected by nurse migration, while Kaestner and Kaushal pursue an instrumental variables strategy. Both draw similar conclusions. These results are interesting in their own right, but it is difficult to extrapolate to other occupations since nursing is primarily female, highly unionized, regulated, and potentially monopsonistic (this last is very controversial, but, minimally, perennial labour shortages are reported). For both studies, a credible identification strategy is crucial since nurses are not randomly assigned employment but end up in particular locations because, for example, opportunities are greatest, social networks exist, and/or information is available. While estimating causal impacts is extremely difficult and it is not clear that either of these strategies identifies the desired parameter perfectly, they are useful exercises. Comparisons across these identification strategies, and across specifications for each, 
are informative. ${ }^{8}$ Altogether, the regression results suggest either no effect, or an extremely small negative effect, on domestic nurses' wages as a result of immigration.

Huang (2011) pursues a similar strategy to the first portion of Schumacher's paper using the NSRN data. She finds those nurses licensed to practice are able to transfer their foreign human capital with relative ease and, indeed, obtain a premium in the labour market. The premium is driven almost entirely by international nursing graduates from English-speaking countries working in hospitals. Even within a narrowly defined occupation, she finds substantial earnings heterogeneity across source country and work environment. Kalist, Spurr, and Wada (2010) undertake research similar to the second part of Schumacher's paper, but using an instrumental variables approach, and find largely consistent results.

An issue raised but not analyzed by Schumacher is host country language ability. Although this is much discussed in the literature and is clearly extremely important in labour markets, relatively little is known about the effect of language facility on earnings and employment outcomes of international immigrants in health professions. Unlike the general labour market, these regulated professions frequently require language proficiency to be tested prior to licensure. A small piece of evidence is provided by Sharieff and Zakus (2006) who interview 21 non-randomly selected IMGs in Canada. Although one of the study’s selection criteria was self-assessed English language fluency, some had appreciable difficulty with the

\footnotetext{
${ }^{8}$ Identification for Schumacher is threatened if, for example, similar to the inclusion of endogenous variables in the economic integration regression in the first half of the paper, the comparison group "over controls" for any wage impact on domestic workers correlated with the local nursing immigration rate. His factor proportion - the locationspecific percent foreign-born (or foreign educated) in nursing - could be picking up general local labour market effects, and might be correlated with similar immigrant percentages in the comparison occupations, with both occupational wage structures responding not only to the common location-specific economic shock (as desired for identification), but also the common effect of immigrants on domestic wages (thereby removing too much of the variance in nursing wages across cities). Inference in Schumacher's paper is also an issue since the inclusion of the percent of nurses who are immigrants implies including a macro variable in the micro regression, which requires appropriate estimation of the standard errors reflecting the "clustered" nature of the data. It is not clear if this was undertaken or not. A controversial assumption that nursing labour markets are not monopsonistic is important for
} 
Test of English as a Foreign Language (TOEFL) and the Test of Spoken English (TSE). Although all passed the TOEFL, it took some four attempts to do so and of the 15 who took the TSE after three attempts only 83 per cent had passed. While not directly relevant to health professionals, a similar problem is noted by Ferrer, Green, and Riddell (2006) among Canadian immigrants in general. There appears sometimes to be a gap between literacy/language skills as measured by these tests and individuals' self perception. This is an important area for future research. $^{9}$

Turning to physicians, recent papers focus on the impact of being granted a license to practice on labour market outcomes. Kugler and Sauer (2005) take advantage of a discontinuity in the relicensing requirements for physicians leaving the former Soviet Union for Israel. Crucially, the Israeli administration assigned immigrant physicians with 20 or more years of experience to an observation track, whereas those with fewer years had to undertake a relicensing exam. The observation track was both immediate and associated with a high probability of licensure whereas the exam track delayed entry to practice and had a lower probability of licensure. While OLS results show a very substantial, in the area of 100 per cent, return to licensure on monthly earnings, the instrumental variable estimates around the discontinuity imply that the causal impact is actually in the range of 180 to 340 per cent. Clearly, the forgone earnings of an immigrant physician not, or being delayed in, receiving a license to practice are enormous.

Given that the instrumental variable results are larger, the authors impute the presence of rents accruing to practitioners and negative selection into licensing. This implies that higher-

Kaestner and Kaushal's approach, and identification in their data is also threatened by weak instruments. Despite these technical challenges, this is an important area in which additional work would be worthwhile.

${ }^{9}$ Other recent work looking at language and immigration includes Chiswick and Miller (2010), Goldmann, Sweetman, and Warman (2011), and the references cited therein. 
quality physicians - those with valuable outside options - are unwilling to bear the cost of acquiring a license. It is not clear how generalizable these results are since the migration of Jews from the former Soviet Union to Israel was part of a large and unusual event, but it does point to a methodology that could easily be used in other countries to evaluate the value of licensure to immigrant practitioners. It also highlights the importance of both licensing criteria and the cost of the licensing process for health professionals, which in most countries is complicated, timeconsuming, and expensive. This is stressed by Sharieff and Zakus (2006). Lesky (2011) outlines the administrative process for physicians entering Canada and the US, and Forcier et al. (2004) is an overview for OECD countries.

In a set of papers, McDonald, Warman, and Worswick (2011a, 2011b) compare immigrants with medical degrees in Canada and the US. Interestingly, although some observers in both countries argue that there is a shortage of physicians, both countries control the number of IMGs who can enter each year and facilitate immigration for physicians willing to work in underserviced areas. One interpretation for this follows from the distinction discussed above between the perspective of patients and payers where cost control is important. Of course, quality control is also important and the two issues frequently intermingle as will be discussed in a subsequent section. Both papers exploit differences in the immigration processes in Canada and the US: Canada has a points system and the US uses employer or State nomination (through the H1-B and J-1 visas). Points systems may be designed in a variety of manners, and may admit new immigrants with medical degrees who have a low probability of being licensed to practice, whereas employer nomination improves the probability of professional employment. ${ }^{10}$ Of course,

\footnotetext{
${ }^{10}$ At times Canada's points system was structured in such a way that physicians without prearranged employment were inadmissible, but since 2002, years of education regardless of field of study/occupation has been a key determinant of points awarded. This permitted physicians to enter with neither pre-arranged employment nor any guarantee of licensure.
} 
immigrant physicians may enter both countries through other administrative channels, such as spousal or refugee streams. Nevertheless, this is an important specific case of the general issue regarding the importance of the details of the administrative implementation of points systems. There may be a gap between the allocation of educational points for immigration and the value of those same credentials for occupational licensing - and Kugler and Sauer's results suggest that that the value of that gap is enormous for applicants if not necessarily for the receiving society.

Comparing an earlier Canadian regime, when it more closely resembled that in the US, to the one following 2002 when the Canadian points system facilitated the entry of highly educated individuals, including physicians, without regard for the likelihood of occupational recognition for regulated/licensed professions, McDonald, Warman, and Worswick observe the emergence of a substantial gap in the probability of practicing. Additionally, immigrants reporting medical education from non-English-speaking countries are more likely to be either not employed or employed in a low skilled occupation. Clearly, the structure of the administrative process adjudicating entry (immigrant selection) into developed countries can have important implications for the ability to practice post-immigration in regulated health professions (and plausibly in other regulated and/or licensed occupations), which have domestic language as well as occupational skill requirements. It appears likely that the Canadian government did not appreciate these ramifications of the legislation, and associated regulations, in shifting the system to more general and generic entrance criteria in 2002. Of course, the licensure process may have biases as discussed below.

A distinct, but related and understudied issue involves practice styles and treatment delivery standards of immigrant practitioners following migration. Chalkley, Tilley, and Wang (2011) compare the practice patterns of comparable in-service foreign and domestically trained 
dentists in Scotland using administrative data. Given the discretion in treatment protocols exercised by health professionals, this is a particularly important issue. Using a difference-indifferences approach, they observe that in particular situations and for male patients, foreign and domestically trained dentists have modestly dissimilar treatment patterns, but these attenuate within two years of post-immigration practice.

\section{Licensing/Registration, Regulation, and Unionization}

Although not a problem exclusive to health professions, immigration for health professionals, as became clear in the previous section, is far more costly, administratively complex, and fraught with risk than is the case for the typical worker. These are important elements in the calculus of migration, a general discussion of which can be found in the chapter in this volume on modelling individual migration decisions. For expositional purposes we categorize the institutional hurdles in health into three "pure" concepts: licensing/registration (with licensure being more common in North America and the approximately synonymous term registration used in Europe), regulation, and unionization. However, we recognize that these terms do not have standardized definitions in the literature, with regulation and licensure/registration sometimes, but not here, being close to interchangeable. Also, in practice the agencies involved frequently implement versions of more than one of these concepts simultaneously. Nevertheless, for our purposes licensure refers to the objective adjudication of skills, knowledge, and abilities. It is an expert assessment of an individual's ability to perform his or her profession safely and in accord with the standards in place in the relevant jurisdiction.

We will define regulation to embody a broader set of goals reflective of the objective function of society in a particular jurisdiction and typically overseen by government. Hence, for 
example, an individual might satisfy a jurisdiction's licensure requirements in that the person has the appropriate qualifications to practice but still might not be granted permission to practice because of, for example, issues regarding the optimal allocation of resources within society. Regulation may be socially beneficial; however, in the extreme, regulation may also reflect an objective that is deemed unethical by some. For example, a regulatory body may exclude or restrict a particular gender or racial group from practicing despite individuals from that group being appropriately qualified (see, e.g., OECD, 2002; Forcier et al., 2004). Regulatory bodies may also intervene by limiting access to educational and training programs providing occupation specific skills. For example, a regulatory body might limit the number of entry positions available in health professional education programs; this is frequently associated with controlling costs.

A trade union or a professional association in this context is an organization that facilitates collective action by the members of a health profession. ${ }^{11}$ Its objective function is not that of society but of its membership. There is a very large literature discussing the economic implications of unionization (see, e.g., Addison and Schnabel, 2003) and a small one looking at the economic operation of medical associations and other provider unions/interest groups that frequently act to protect their members from increased competition that might reduce incomes (e.g., Drexler, 2008; McGuire, 2000).

Internationally, some jurisdictions believe that the conflict between the alternative functions and perspectives requires distinct organizations, whereas others do not. ${ }^{12}$ At issue in

\footnotetext{
${ }^{11}$ In some jurisdictions certain health professions, for example physicians, have tended to shy away from the term "union", whereas others, for example nurses, have used this nomenclature.

${ }^{12}$ Perhaps most commonly there is a distinction between the union/association that serves the professional membership and a regulatory college (at arm's-length from, or a branch of, government) comprised primarily of experts from within the profession but whose duty is to serve the broader social perspective. In this context the college is sometimes charged with licensure, although that is sometimes administered directly by government.
} 
this context is that migrating health professionals need to navigate a series of competency tests, credential verifications, and location-specific hurdles motivated by social and/or professional objective functions. Having appropriate qualifications is not sufficient to practice in many jurisdictions.

A very long and at times controversial economic literature looks at licensure/regulation/unionization in health professions (Friedman, 1962; Arrow, 1963; Kleiner and Kudrle 2000; and Inoue, 2010), and most studies conclude that while a socially beneficial function is served on average, on the margin licensing practices satisfy a union/association motive more than a socially beneficial regulatory one.

Overall, more so than for most occupations, institutions are crucial for migrants who are health professionals and for consumers of immigrant health services. For instance, Noether (1986) shows that the ease with which foreign medical graduates can practice in the US is a key element of the degree of competition on the health labour market in that country. Credentialing and licensing bodies, regulatory agencies, and professional associations/trade unions all play important roles serving distinct and sometimes conflicting purposes. In many countries the role and function of these institutions is not well studied from an economics perspective, and international comparisons are likely to yield fruitful insights in the future regarding the strengths and weaknesses of alternative structures.

In this respect, country-to-country bilateral agreements can play a very important role in regulating the migration of health professionals. Inoue shows these are common, and he also points to the legal and practical conflicts in some jurisdictions, especially the EU, around language requirements. From an industrial relations perspective and with reference to the international migration of nurses to the UK, Bach (2007) similarly notes the importance of 
bilateral agreements that allow the tailoring of professional education in one country to the requirements of another. He views the institutional and regulatory framework as crucial to the short term operation of the immigration process for health professionals and describes current trends being towards internationalization rather than globalization. Manning and Sidorenko (2007) also look at the importance of regulatory frameworks but focus on migration within a trading arrangement among ten Southeast Asian nations with an emphasis on the supranational influence of mode 4 under the General Agreement on Trade in Services (GATS). ${ }^{13}$ They observe that more developed economies have more liberal regulations regarding worker mobility, and comparing the information technology and healthcare sectors they find healthcare to be more highly regulated given both social considerations and professional interests.

\section{A DEVELOPING COUNTRY PERSPECTIVE}

Many developing countries face a crisis in healthcare due to a crippling shortage of health professionals. While emigration to developed countries is not the only source of the problem, it is an important aspect of the issue. In sub-Saharan Africa the shortage is particularly acute, and Dal Poz and Gupta (2009) estimate that 36 countries do not have sufficient workers to provide minimal services for maternal, newborn, and child health. Important externalities arise from the health of the population, which is influenced by the size and quality of the health workforce. In particular, although causality goes in multiple directions, improved population health can lead to a higher growth rate of GDP and more rapid economic development. Many observers, therefore, see this as not only affecting the current, but also the future, well-being of a nation's population.

\footnotetext{
${ }^{13}$ However, GATS' application to the healthcare sector has limitations since it does not cover public services, that is, services provided under government authority where there is neither a commercial nor competitive basis.
} 
A very large research and advocacy literature exists discussing the migration of health professionals from less-developed to developed countries. Although somewhat arbitrary, research can be classified as falling within academic disciplines, primarily: medical, although typically not clinical (e.g., Mills et al., 2011; and Mullan, 2005); health services (e.g., Parkash et al., 2006; Zurn et al., 2004, is a review); development (e.g., Beine et al. 2001); or health economics (overviews are Rutten, 2009b, and section 21.4.3 of Bärnighausen and Bloom, 2011; examples are Kangasniemia, Winters, and Commander, 2007; and Hagopian et al., 2005).

\section{Data}

It is very difficult to obtain information globally, but the WHO, OECD and World Bank have led in developing consistent and internationally comparable data on the migration of health professionals looking both at developed and developing countries (e.g., OECD, 2007a; Diallo, 2004; Bhargava and Docquier, 2007). Despite this, a lack of detailed comparable data tends to cause research projects to be narrowly defined on one dimension or another. Most empirical studies either focus on the flow or stock of (immigrant) health professionals in individual or a small set of source or receiving countries - frequently with a focus on physicians or nurses. Some, such as Mills et al. (2011), calculate the cost of the lost human capital and/or productivity to the source country, others measure the value of the benefit to the receiving country. Another stream, such as Goldfarb, et al., (1984), focus on remittances with some evidence that this revenue on average more than makes up for the loss to source countries and explains why some developing countries and/or medical schools in those countries have effectively set themselves up as exporters. However, even if some countries benefit from the export of health professionals, this does not take away from the healthcare crisis that they and other developing countries face. 


\section{Push and Pull Factors, and "Beneficial" Migration}

A number of studies address the "push and pull" factors that motivate health professionals to migrate (Rutten, 2009b, and Bärnighausen and Bloom, 2011, provide an extensive catalogue of studies; Astor, 2005, provides an extensive opinion survey). One particularly interesting observation by Vujicic et al. (2004) is that the gap in earnings between source and destination countries is so enormous that no plausible increase in source country wages will have an effect on emigration rates. All told, there is a substantial list of financial and nonfinancial reasons. One central conclusion from this stream of research is that there is no single "magic bullet" that will stop health professional migration, nor is it obvious that stopping migration altogether would be beneficial. Rather, managing the migration flow is a more realistic approach to protecting developing nations' investments and serving their populations' healthcare needs. Developing countries that manage their health professional education systems with an eye on graduates’ migration decisions will be able to extract greater benefits for their populations; if nothing else active management may increase remittances and/or obtain offsets for the costs of education.

The concept of managed migration coincides with the development of bilateral and multilateral national agreements as discussed regarding licensure above. Although this will clearly not solve all the relevant problems, formalizing some of the key relationships may provide management tools to both sending and receiving governments. One trend that is evident is the movement of migrant health professionals within or across sets of countries with common or closely related languages. Even more so than with the average immigrant, practicing in a 
health profession requires advanced language skills - and these skills are frequently tested. This appears to be a key motivating factor for relevant existing international agreements.

One particularly important hypothesis justifying the receipt of economic migrants from less developed countries by developed countries is that the source countries benefit from the exchange. One aspect of this idea, by Stark and Wang (2002), envisions migration as a type of "prize" that may motivate human capital development in source countries and, despite the loss of a limited number of workers, raise the overall quality and level of training in those countries.

While there is some appeal to the theoretical possibility of emigration that is "beneficial" to the source country, empirical research is mixed. Kangasniemi et al. (2007) seek to determine whether the conditions required for immigration to be beneficial exist for a particular set of countries and conclude that they do not - although these authors observe that return migration and/or remittances do have beneficial effects for the sending country. In contrast, looking at national immigrant populations as a whole rather than focusing on health professionals, Beine et al. (2008) find some support for the hypothesis in countries with both low levels of human capital and low emigration rates. It may well be that the beneficial effect turns on being able to control emigration; also, education programs in healthcare typically have excess demand and limited enrollment, and this may differentiate these fields of study. Bhargava, Docquier, and Moullan (2011), using an extremely large dataset of countries from 1991 to 2004 and appropriate panel data techniques, find physician migration indeed induces increased levels of medical education, but the magnitude is too small for a beneficial effect. See Bhargava and Docquier (2007) for an introduction to the useful and interesting dataset employed. However, they also observed that child mortality rates decrease as physician density increases but only when aggregate literacy rates are sufficiently high. They conclude that reducing medical brain drain 
will only have modest benefits. Clearly, medical workforce availability is only one element of the healthcare system and social structure required for improved health outcomes.

\section{CONCLUSION}

International immigration of health professionals has substantial externalities for both developed and developing nations. Developing nations are frequently negatively affected by the phenomenon, but for these nations it appears to be but one element of a larger systemic health challenge. Mobility is primarily towards higher-paying, more prestigious, more amenity-rich, areas. Health professionals migrate from rural to urban, from low to middle to high income countries, from developed countries with lower wages to those with higher ones. Less developed countries are most likely to be net suppliers, and although other developed countries are also net recipients the main receiver appears to be the US. Extensive multinational datasets have recently been developed that can extend the scope of future analyses addressing many of these issues. Shortages of domestically trained health professionals in developed nations are a key driver affecting the human resource losses of developing nations. Since the health workforce supply in wealthy countries is, by one means or another, influenced and/or controlled by governments, many of the perceived shortages driving the observed migration appear to result from planning errors or historical decisions putting substantial weight on short-term concerns and/or relying on immigration. A better understanding of these dynamics could improve planning to alleviate future shortages and thereby assist less developed countries.

Quantifying and better understanding both the stocks and flows of health human resources, especially in developing countries but also in developed ones, seems extremely worthwhile. Much of the research thus far is foundational and primarily descriptive, but a few 
studies are more analytical, and some seek not just correlations but causal impacts. A few papers looking at the economic integration, and causal impacts resulting from, the arrival of international health professionals have been written - mostly for the US. But the issues of asymmetric information and moral hazard in healthcare delivery that are reflected in health labour markets in the form of, for example, government regulation, licensure and other forms of practice standards have not been yet integrated into the immigration literature to any great degree. To this point it appears that among new immigrants employed in a health profession, economic integration occurs relatively swiftly, and their arrival causes a relatively small or negligible negative impact on the domestic labour force. However, most of these studies tend to focus on immigrants who find employment, ignoring those unable to work in the profession in which they were trained. In the case of physicians, one study suggests that the opportunity cost of not practicing is enormous, suggesting substantial rents.

Management tools that governments may potentially employ, for example bilateral and multilateral treaties facilitating recognition and occupational integration, also seem particularly interesting and worthy of study both to provide feedback regarding their design and implementation, and as sources of exogenous variation to allow underlying economic parameters to be estimated. In sum, there is enormous scope for future work, both in establishing the basic stylized facts and in understanding and economically modeling the underlying market structures. 


\section{REFERENCES}

Addison, John T. and Claus Schnabel (2003), International Handbook of Trade Unions, Cheltenham, UK and Northampton, MA, USA: Edward Elgar Publishing.

American Medical Association (2010), International medical graduates in American medicine: contemporary challenges and opportunities, Chicago: International Medical Graduates Section Governing Council.

Arrow, Kenneth. J. (1963), 'Uncertainty and the welfare economics of medical care', American Economic Review, 53 (5), 941-973.

Astor, Avraham, Tasleem Akhtarb, et al. (2005), 'Physician migration: Views from professionals in Colombia, Nigeria, India, Pakistan and the Philippines', Social Science \& Medicine, 61, 24922500 .

Auda, Rick, Amanda Ross and David Vardy (2005), 'The use of provisionally licensed international medical Graduates in Canada', Canadian Medical Association Journal, 173 (11), 1315-1316.

Bach, Stephen (2007), 'Going global? The regulation of nurse migration in the UK', British Journal of Industrial Relations, 45 (2), 383-403.

Bärnighausen, Till, and David. E. Bloom (2011), “The global health workforce”, in Sherry Glied and Peter C. Smith (eds.), Oxford Handbook of Health Economics, Oxford: Oxford University Press, pp. 486-519.

Bärnighausen, Till, and David. E. Bloom (2009), 'Financial incentives for return of service in underserved areas: a systematic review’, BMC Health Services Research, 9 (86).

Beine, Michael, Fréderic Docquier, Hillel Rapoport (2008), 'Brain drain and human capital formation in developing countries: winners and losers', The Economic Journal, 118 (528) 631652.

Docquier, F., and Bhargava, A. (2007), 'A new panel data set on physicians' emigration rates (1991-2004)’. Working paper, Catholic University of Louvain. http://perso.uclouvain.be/frederic.docquier/filePDF/MBD1_Description.pdf

Beine, Michael, Fréderic Docquier, Hillel Rapoport (2001), 'Brain drain and economic growth: theory and evidence', Journal of Development Economics, 64 (1), 275-289.

Bhargava, Alok, Frédéric Docquier, and Yasser Moullan (2011) "Modeling the effects of physician emigration on human development” Economics and Human Biology, 9, 2, 172-183. 
Bloor, K. and A. Maynard (2003), 'Planning human resources in health care: towards an economic approach - an international comparative review’, Canadian Health Services Research Foundation, Ottawa, ON, Canada, available at http://www.chsrf.ca (accessed 10 October 2011).

Canadian Federal/Provincial/Territorial, Advisory Committee on Health Delivery and Human Resources, ACHDHR (2009), 'How many are enough? Redefining self-sufficiency for the health workforce', A Discussion Paper, Health Canada, Ottawa, available at http://www.hcsc.gc.ca/hcs-sss/pubs/hhrhs/2009-self-sufficiency-autosuffisance/index-eng.php (accessed July 2010).

Chalkley, Martin, Colin Tilley, Shaolin Wang (2011), 'Comparing the treatment provided by migrant and non-migrant health professionals: dentists in Scotland', Dundee Discussion Papers in Economics, Working Paper No. 249., Department of Economic Studies, University of Dundee, Scotland.

Chiswick, Barry R. and Paul W. Miller (2010), 'Occupational language requirements and the value of English in the United States labor market', Journal of Population Economics, 23 (1), 353-72.

Dal Poz, Mario R. and Neeru, Gupta, (eds) (2009), Handbook on Monitoring and Evaluation of Human Resources for Health with special applications for low- and middle-income countries. Geneva: World Health Organization.

Denour, Linda and Rémi Junker (1995), 'Les médecins étrangers dans les hôpitaux français", Revue Européenne des Migrations Internationales, 11 (3), 145-146.

Denton, F.T., A. Gafni, and B.G. Spencer (2009), 'Users and Suppliers of Physician Services: A Tale of Two Populations’ International Journal of Health Services, 39 (1), 189-218.

Diallo, K. (2004), Data on the migration of health-care workers: sources, uses, and challenges. Bulletin of the World Health Organization, 82 (8), 601-607.

Drexler, Armelle (2008), 'Le défi du recrutement des médecins à diplômes étrangers dans les hôpitaux publics’, Mémoire de fin d'études, Ecole des Hautes Etudes en Santé Publique.

Ferrer, Ana, David A. Green and Craig W. Riddell (2006), 'The effect of literacy on immigrant earnings', Journal of Human Resources, 41 (2), 380-410.

Forcier, M. B., S. Simoens and A. Giuffrida (2004), 'Impact, regulation and health policy implications of physician migration in OECD countries', Human Resources for Health, 2, 12.

Friedman, Milton (1962) Capitalism and Freedom. Chicago and London, IL, USA: The University of Chicago Press. 
Goldmann, Gustave, Arthur Sweetman and Casey Warman (2011), 'The portability of new immigrants' human capital: language, education and occupational matching', IZA Discussion Paper 5851, Institute for the Study of Labor, Bonn.

Goldfarb, Robert, Oli Havrylyshyn and Stephen Mangum (1984), 'Can remittances compensate for manpower outflows: The case of Philippine physicians' Journal of Development Economics, 15 (1-3), 1-17.

Grobler, L., B. J. Marais, S.A. Mabunda, P. N. Marindi, H. Reuter, and J. Volmink (2009), 'Interventions for increasing the proportion of health professionals practising in rural and other underserved areas’, Cochrane Database of Systematic Reviews, Issue 1. Art. No.:CD005314.

Haberkern, K., T. Schmid, F. Neuberger and M. Grignon (2012), 'The role of the elderly as providers and recipients of care’, in The Future of Families to 2030, OECD, pp. 189-257.

Hagopian, Amy, Matthew J. Thompson, Emily Kaltenbach and Gary L. Hart (2003), 'Health departments' use of international medical graduates in physician shortage areas,' Health Affairs, 22(5), 241-249.

Hagopian, Amy, Anthony Ofosu, et al. (2005), 'The flight of physicians from West Africa The flight of physicians from West Africa: Views of African physicians and implications for policy', Social Science and Medicine, 61, 1750-1760.

Hawthorne, Lesleyanne and Jan Hamilton (2010), 'International medical students and migration: the missing dimension in Australian workforce planning?’ Medical Journal of Australia, 193(5), 262-265.

Hirsch, Barry T., and Edward J. Schumacher (2005), 'Classic or new monopsony? Searching for evidence in nursing labor markets’, Journal of Health Economics, 24, 969-989.

Huang, Serana H. (2011), 'The international transferability of human capital in nursing', International Journal of Health Care Finance and Economics, 11(3), 145-163.

Inoue, Jun (2010), 'Migration of nurses in the EU, the UK, and Japan: regulatory bodies and push-pull factors in the International mobility of skilled practitioners', Discussion Paper Series A No.526, Institute of Economic Research, Kunitachi, Tokyo.

Kaestner and Kaushal (2012), 'Effects of immigrant nurses on labour market outcomes of US nurses’, Journal of Urban Economics, 71, 219-229.

Kalist, David, Stephen Spurr and Tatsuma Wada (2010), 'Immigration of nurses', Industrial Relations, 49(3), 406-427.

Kanchanachitra Churnrurtai, Magnus Lindelow, et al. (2011), 'Human resources for health in southeast Asia: shortages, distributional challenges, and international trade in health services', Lancet, 377, 769-781. 
Kangasniemi, Mari, Alan L. Winters, Simon Commander (2007), 'Is the medical brain drain beneficial? Evidence from overseas doctors in the UK', Social Science and Medicine, 65(2007), 915-923.

Kleiner, Morris M. and Robert T. Kudrle (2000), 'Does regulation affect economic outcomes? The case of dentistry’, Journal of Law and Economics, 43(2), 547-582.

Kugler, Adriana, D. and Robert M. Sauer (2005), 'Doctors without borders? Relicensing requirements and negative selection in the market for physicians', Journal of Labor Economics, 23(3), pp. 437-465.

Lesky, Linda G. (2011), 'Physician migration to the United States and Canada: criteria for admission’, in Barry R. Chiswick (ed.), High-Skilled Immigration in a Global Labor Market, Washington, DC, USA: American Enterprise Institute Press, pp. 155-164.

Machin, Stephen and Alan Manning (2004), 'A test of competitive labor market theory: the wage structure among elder care assistants in the South of England' Industrial and Labor Relations Review, 57(3), 370-385.

Manning, Chris and Alexandra Sidorenko (2007), 'The regulation of professional migration: insights from the health and IT sectors in ASEAN', The World Economy, 30(7), 1084-1113.

Masselink, Leah E. and Shoou-Yih Daniel Lee (2010), 'Nurses, Inc.: Expansion and commercialization of nursing education in the Philippines', Social Science and Medicine, 71, 166-172.

McAvinue, Mary B., John R. Boulet, et al. (2005), 'U.S. citizens who graduated from medical schools outside the United States and Canada and received certification from the educational commission for foreign medical graduates, 1983-2002', Academic Medicine, 80 (5), 473-478.

McDonald, James Ted, Casey Warman and Christopher Worswick (2011a), 'Earnings, occupation and schooling decisions of immigrants with medical degrees: evidence for Canada and the US', in Barry R. Chiswick (ed.), High-Skilled Immigration in a Global Labor Market, Washington, DC, USA: American Enterprise Institute Press, pp. 165-197.

McDonald, James Ted, Casey Warman and Christopher Worswick (2011b), 'Immigrant selection systems and occupational outcomes of international medical graduates in Canada and the United States’, Queen’s Economics Department, Canada, Working Paper 1285.

McDonald, James Ted and Christopher Worswick (2010) 'The determinants of the migration decisions of immigrant and non-immigrant physicians in Canada’, SEDAP Research Paper No. 282, McMaster University, Canada. 
McGuire, Thomas G. (2011), 'Physician agency and payment for primary medical care', in Sherry Glied and Peter C. Smith (eds.), Oxford Handbook of Health Economics, Oxford: Oxford University Press, pp. 602-623.

McGuire, Thomas. G (2000), 'Physician agency', in Anthony J. Culyer and Joseph P. Newhouse (eds.), Handbook of Health Economics 1A, Amsterdam, The Netherlands: North-Holland and Elsevier, pp. 461-536.

Mills, Edward J., Steve Kanters, et al. (2011), 'The financial cost of doctors emigrating from sub-Saharan Africa: human capital analysis’, British Medical Journal, 343, 1-13.

Mullan, Fitzhugh (2005), 'The metrics of the physician brain drain', New England Journal of Medicine, 353, 1810-1818.

Noether, Monica (1986), 'The Growing Supply of Physicians: Has the Market Become More Competitive? Journal of Labor Economics, 4(4), 503-537.

Norwegian Directorate of Health and Social Affairs (2007), 'Recruitment of health workers: towards global solidarity’, Department of health and social services personnel/Secretariat for international work, Rapport IS-1490 E, Sosial-og Helsedirektorate, Oslo, Norway: available at http://www.helsedirektoratet.no/publikasjoner/recruitment-of-health-workers-towards-globalsolidarity/Sider/default.aspx (accessed 12 October 2011).

Nullis-Kapp, C. (2005), 'Efforts under Way to Stem “Brain Drain” of Doctors and Nurses', Bulletin of the World Health Organization, 83(2), 84-85.

OECD (2002), International Migration of Physicians and Nurses: Causes, Consequences and Health Policy Implications (Paris: OECD).

OECD (2007a), International migration outlook 2007. Paris: Organisation for Economic Cooperation and Development.

OECD (2007b), OECD Factbook 2007: Economic, Environmental and Social Statistics. Paris: Organisation for Economic Co-operation and Development.

OECD (2008), The Looming Crisis in the Health Workforce How Can OECD countries respond? Paris: OECD Health Policy Studies, Organisation for Economic Co-operation and Development.

OECD (2011), OECD Factbook 2011: Economic, Environmental and Social Statistics. Paris: Organisation for Economic Co-operation and Development.

Parkash, Hari, Mathur; R. Duggal and B. Jhuraney (2006), 'Dental workforce issues: A global concern', Journal of Dental Education, 70(11), S22-S26. 
Rabinowitz, Howard. K., James. J. Diamond, Fred. W. Markham and Jeremy. R. Wortman (2008), 'Medical school programs to increase the rural physician supply: a systematic review and projected impact of widespread replication’, Academic Medicine, 83(3), 235-243.

Rutten, Martine (2009a), 'The economic impact of medical migration: a receiving country’s perspective’, Review of International Economics, 17(1), 156-171.

Rutten, Martine (2009b), 'The economic impact of medical migration: an overview of the literature’, The World Economy, 291-325.

Schaafsma, Joseph and Arthur Sweetman (2001), 'Immigrant earnings: age at immigration matters’, Canadian Journal of Economics, 34(4), 1066-1099.

Schumacher, Edward, J. (2011), 'Foreign-born nurses in the US labor market', Health Economics 20, 362-378.

Sharieff, Waseem and David Zakus (2006), 'Resource utilization and costs borne by international medical graduates in their pursuit for practice license in Ontario, Canada', Pakistan Journal of Medical Sciences, 22(2), 110-115.

Staiger, Douglas O., Joanne Spetz and Ciaran S. Phibbs (2010), 'Is there monopsony in the labor market? Evidence from a natural experiment', Journal of Labor Economics, 28(2), 211-236.

Stark, Oded and Yong Wang (2002), 'Inducing human capital formation: migration as a substitute for subsidies’, Journal of Public Economics, 86(2002), 29-46.

United Kingdom Department of Health (2011), 'International Recruitment - Code of Practice' available at http://www.nhsemployers.org/ RecruitmentAndRetention/InternationalRecruitment/ Code-of-Practice/Pages/Code-practice-international-recruitment.aspx, (accessed 14 December 2011).

United States Government Accountability Office (2006), Foreign Physicians Data on Use of J-1 Visa Waivers Needed to Better Address Physician Shortages, Washington, DC: Government Accountability Office, GAO-07-52.

Vujicic, Marko, Pascal Zurn, et al. (2004), 'The role of wages in the migration of health care professionals from developing countries’, Human Resources for Health, 2, 3.

WHO (2006), Working Together for Health, the World Health Report 2006. Geneva: World Health Organization.

WHO (2010), Global Code of Practice on the International Recruitment of Health Personnel Sixty-third World Health Assembly-WHA63.16, Geneva: World Health Organization. 
Wismar Mathias, Claudia B.Maier, et al. (eds) (2011), Health Professional Mobility and Health Systems: Evidence from 17 European Countries, Copenhagen: World Health Organization, on behalf of the European Observatory on Health systems and Policies.

Wilson, Nathan W., Ian D. Couper, et al. (2009), 'A critical review of interventions to redress the inequitable distribution of healthcare professionals to rural and remote areas', Rural Remote Health, 9, 1060.

Zurn, Pascal, Mario R Dal Poz, Barbara Stilwell and Orvill Adams (2004), 'Imbalance in the health workforce', Human Resources for Health, 2, 13. 
Table 1 - Foreign born and foreign trained in selected OECD countries circa 2000

\begin{tabular}{lccccc} 
& \multicolumn{2}{c}{ Physicians } & \multicolumn{3}{c}{ Nurses } \\
\cline { 1 - 3 } Country & $\begin{array}{c}\text { Foreign } \\
\text { Trained }\end{array}$ & $\begin{array}{c}\text { Foreign } \\
\text { Born }\end{array}$ & & $\begin{array}{c}\text { Foreign } \\
\text { Trained }\end{array}$ & $\begin{array}{c}\text { Foreign } \\
\text { Born }\end{array}$ \\
\cline { 1 - 3 } \cline { 5 - 6 } Australia & $(\%)$ & $(\%)$ & & $(\%)$ & $(\%)$ \\
Austria & 25.0 & 42.4 & & 12.1 & 24.5 \\
Canada & 1.8 & 14.6 & & -- & -- \\
Switzerland & 23.1 & 35.1 & & 6.4 & 17.2 \\
Denmark & 11.8 & 27.9 & & -- & -- \\
Finland & 7.7 & 10.9 & & 6.0 & 4.1 \\
France & 3.6 & 3.9 & & 0.2 & 0.8 \\
United Kingdom & 3.9 & 16.9 & & -- & -- \\
Ireland & 33.1 & 33.7 & & 8.0 & 15.2 \\
Netherlands & 10.3 & 35.3 & & 14.0 & 14.3 \\
New Zealand & 6.2 & 16.6 & & 1.4 & 6.8 \\
Sweden & 34.5 & 46.8 & & 19.3 & 23.1 \\
United States & 4.3 & 22.8 & & 2.5 & 8.8 \\
\hline
\end{tabular}

Source: OECD (2007a,b) and OECD (2011).

Notes: Foreign trained MDs for Australia, UK and Netherlands, and foreign trained nurses for Australia, Ireland, Netherlands and United States, are 2005 data. 
Table 2 Emigration and immigration of physicians among Australia, Canada, UK and US

\begin{tabular}{|c|c|c|c|c|c|c|c|}
\hline \multicolumn{8}{|c|}{ Immigration } \\
\hline & & Australia & Canada & UK & US & Total Out & $\%$ \\
\hline \multirow{6}{*}{ 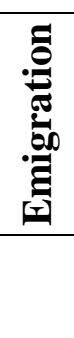 } & Australia & 54,212 & 247 & 872 & 1,144 & 2,263 & $4.2 \%$ \\
\hline & Canada & 65 & 68,096 & 50 & 8,990 & 9,105 & $13.4 \%$ \\
\hline & UK & 4,664 & 2,735 & 138,667 & 3,439 & 10,838 & $7.8 \%$ \\
\hline & US & 73 & 519 & 79 & 836,036 & 671 & $0.1 \%$ \\
\hline & Total In & 4,802 & 3,501 & 1,001 & 13,573 & -- & -- \\
\hline & $\%$ & $8.9 \%$ & $5.1 \%$ & $0.7 \%$ & $1.6 \%$ & -- & -- \\
\hline
\end{tabular}

Source: Mullan (2005). 
Figure 1: $\quad$ Share of physicians and total population that is foreign born, OECD countries circa 2000 (\%)

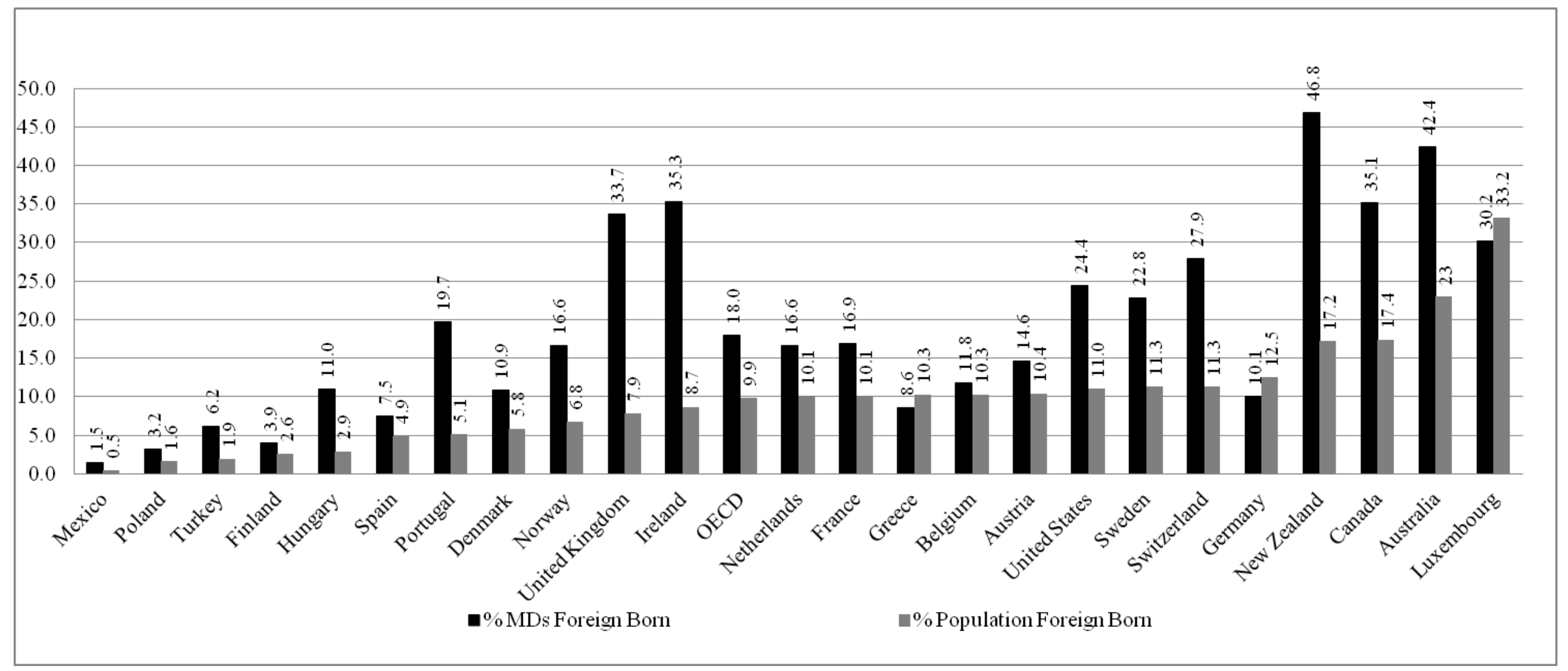

Sources: OECD (2007a, b) and OECD (2011).

Notes: Poland and Greece's population are from OECD (2007b); all others are from OECD (2011). 
Figure 2: $\quad$ Share of nurses and total population that is foreign born, OECD countries circa 2000 (\%)

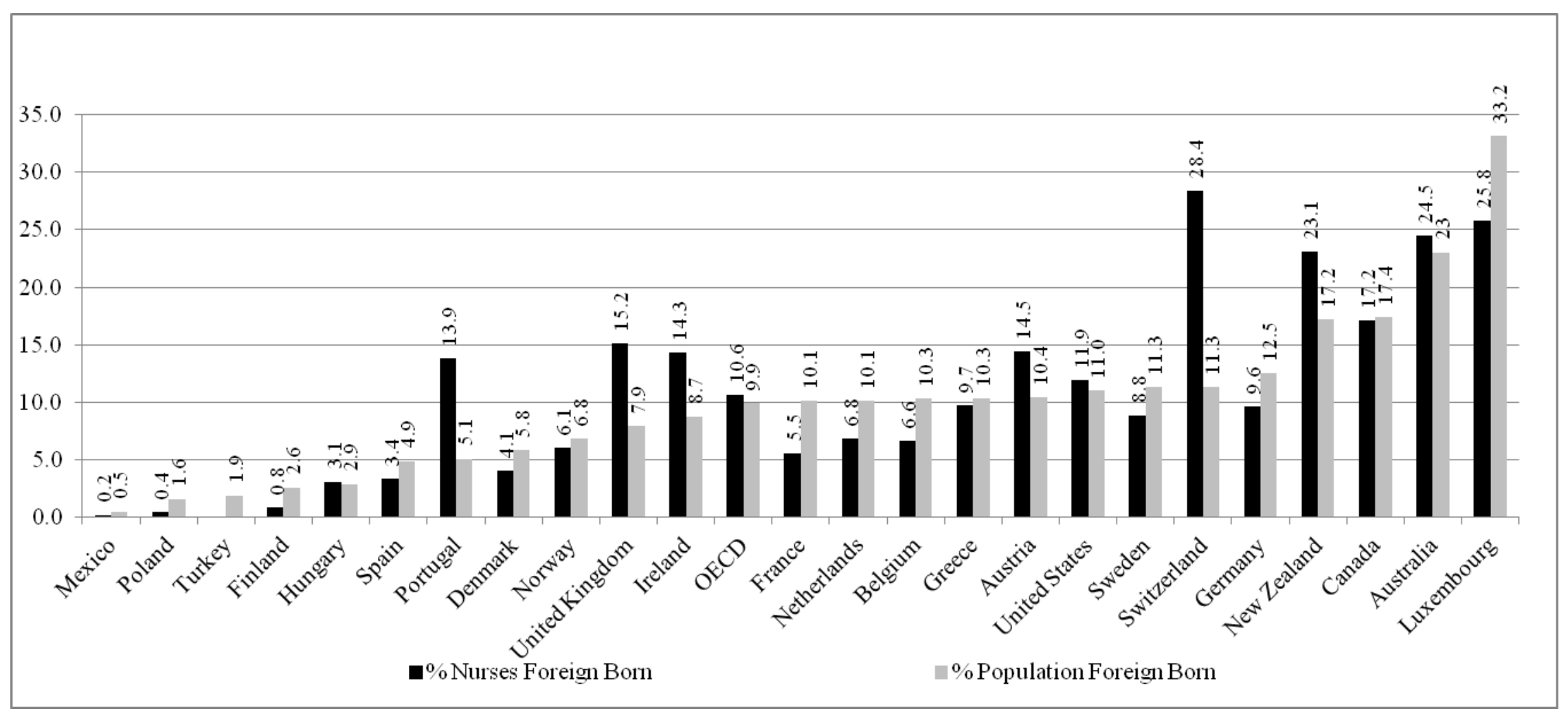

Sources: OECD (2007a, b) and OECD (2011). 
Figure 3: $\quad$ Share of other health professionals and total population that is foreign born, OECD countries circa 2000 (\%)

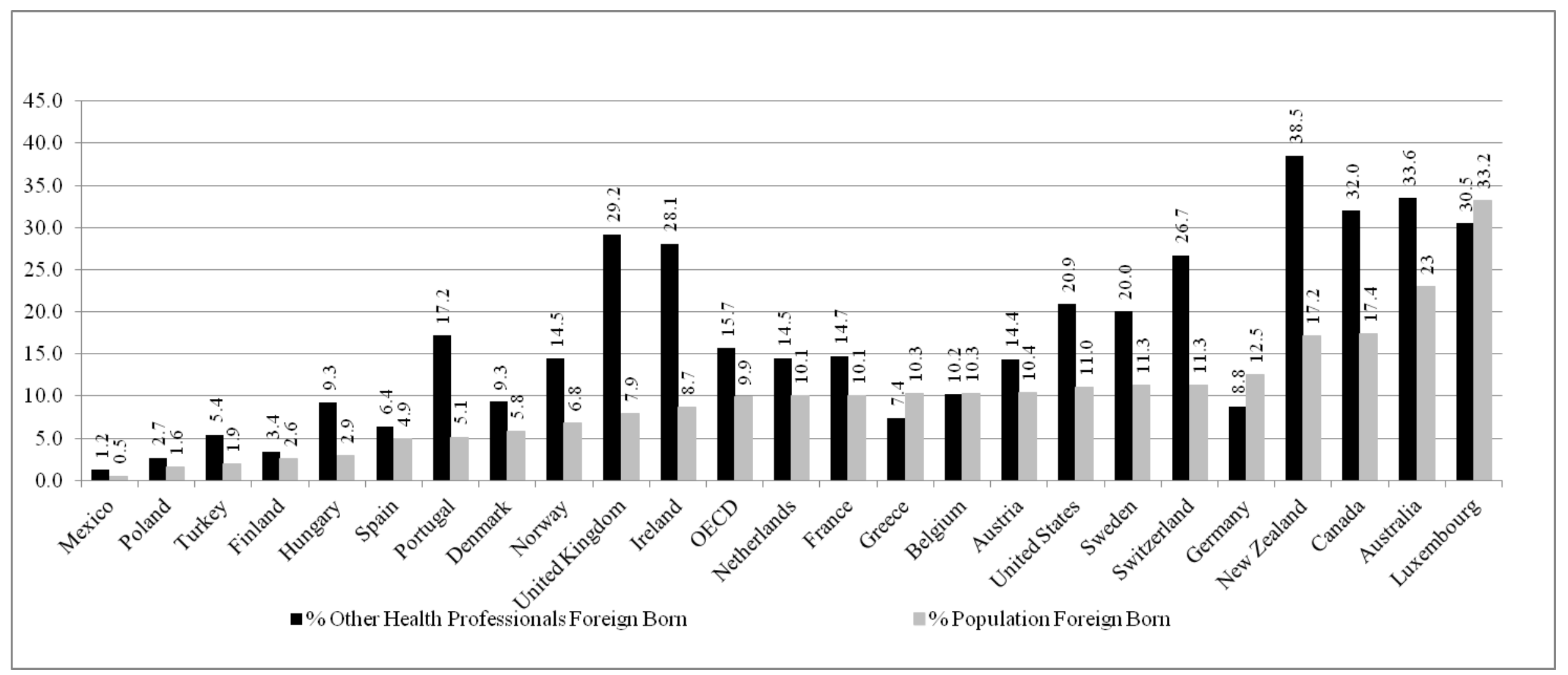

Sources: OECD (2007a, b) and OECD (2011).

Notes: Other professions defined as ISCO 222: dentists, pharmacists, veterinarians and other health professionals not elsewhere classified. 